\title{
Contextual Inquiry: A Systemic Support for Student Engagement through Reflection
}

\author{
Peter Bednar \\ University of Portsmouth, UK; \\ and Lund University, Sweden \\ peter.bednar@ics.lu.se
}

\author{
Roger Eglin and \\ Christine Welch \\ University of Portsmouth, UK \\ roger.eglin@port.ac.uk \\ christine.welch@port.ac.uk
}

\begin{abstract}
Much research has been published which attests to desire felt by educators to improve the quality of student reflection, and engagement with learning, through processes of assessment. This paper describes how research in Systems Analysis is being transformed and applied to educational practice. Staff considered that methods were needed to stimulate students to reflect and engage in higher orders of learning in order to help them to experience 'success' in their assessments. The paper describes the background to a Systems Analysis approach and its specific adaptation for support in student learning in the field of creative technologies.
\end{abstract}

Keywords: Contextual Inquiry; Double-loop Learning; student engagement; creative technologies.

\section{Introduction}

Bump, bump, bump goes Pooh bear's head as Christopher Robin comes down the stairs dragging Pooh bear's foot, surely there must be another way of coming down the stairs thinks Pooh, if only I could stop bumping my head and think for a minute.... (Derived from A.A. Milne, "Winnie-thePooh")

In the environment of higher education in the 21 st century, we find ourselves surrounded by increasing levels of complexity. Our students have learned to become learners in a world which is information rich, and in which data bombard them from many different media and channels. At the same time, the demands upon their time are ever greater as they try to come to terms with studies, which may be interdisciplinary in nature. This view is encapsulated by Ramsden (2003) as follows:

"We work in surroundings that our colleagues of thirty years ago would not recognize. Higher

Material published as part of this journal, either on-line or in print, is copyrighted by the publisher of the Informing Science Journal. Permission to make digital or paper copy of part or all of these works for personal or classroom use is granted without fee provided that the copies are not made or distributed for profit or commercial advantage AND that copies 1) bear this notice in full and 2) give the full citation on the first page. It is permissible to abstract these works so long as credit is given. To copy in all other cases or to republish or to post on a server or to redistribute to lists requires specific permission and payment of a fee. Contact Publisher@ijklo.org to request redistribution permission. education has become part of a global shift to a new way of creating and using knowledge. The new way is focused on solving problems and is sensitive to customer needs. It strives for quantity as well as quality. It cuts across discipline boundaries. It is enlivened by apparently infinite quantities of instantly accessible information." (p.3) 
This experience is especially highlighted in the new disciplines of the Creative Technologies that have their origins in developments in Information Technology. For example, the Department of Creative Technologies at the University of Portsmouth specializes in areas where new technology is impacting in the Arts, Leisure and Entertainment. It specializes in subjects like web technologies, graphics, animation, virtual reality, video, audio and music. Courses are offered that cover computer animation, development of computer games for PC and gaming consoles, such as Sony Playstation and Xbox, and Nintendo Game Cube, etc.

How then do we help our students to structure the uncertainty brought about by a constantly changing kaleidoscope of information, and help them start to make sense of their studies in these subject areas? As educators, we need to find new ways to support students to engage with their learning processes. Examples include Problem Based Learning or Inquiry Based Learning. A useful discussion of Problem Based Learning can be found in Gackowski (2003). Such approaches need to permeate the whole educational experience from presentation of new ideas to assessment of learning outcomes. In this paper, the authors will attempt to address this latter aspect of the learning cycle.

There is evidence to show that students and their teachers do not always have clear agreement about what is demonstrated through the assessment process. For example, Brown, Bull, \& Pendlebury (1997) report the results of a series of interviews in which students were invited to explain what they understood by 'learning'. A range of definitions emerged:

- Learning as an increase in knowledge. These students apparently saw themselves as acquiring this 'commodity' from their tutors;

- Learning as memorizing. Here students appeared to see their task as storage of the said 'commodity' for a temporary period;

- Learning as acquiring facts or procedures which to be used - skills, algorithms, formulae. These they appeared to see as means to particular ends, e.g. as background to later material or for use in an examination;

- Learning as making sense. These students appeared to make active attempts to abstract meaning in a process of learning so that they could describe their methods and reasoning, as well as answers to problems or tasks;

- Learning as understanding 'reality'. This group of students appeared to see learning as personally meaningful. They described a transformation in perceptions of the world before and after learning.

If many educators aspire to encourage this last approach, then we would argue that ways must be found to alter student perceptions of learning processes. We would argue that one possible route to this objective could be to support them to engage in reflection upon their activities. In the next section of this paper, we will consider how motivation to learn may come about as a response to uncertainty. We will go on to discuss learning processes, and the role of reflection in these processes. In the next section of the paper, we will discuss a method for contextual inquiry the Strategic Systemic Thinking Framework (SST) and suggest how an adaptation of this method Strategic Systemic Learning (SSL) has been used to promote a higher order of learning through assessment activities of students in the Dept. of Creative Technologies at the University of Portsmouth.

\section{Background}

When faced with new and unfamiliar concepts and activities, individuals may experience their problem space as unstructured. Weick (1995) discusses ways in which individuals in organizations may transform a perceived problem space which is unstructured (uncertain) into a structured 
uncertainty, through sense-making processes. In attempting to make sense of an unstructured problem, a person may be trying to move from a position of not knowing what to do, to a position of 'knowledge' about a range of alternative possibilities from which a solution might be created, i.e. ambiguity. We would suggest that students approach learning experiences in a similar way. In many instances, a desire to reach an early resolution of uncertainty can lead to over-simplification of complex problem-spaces. This may account for the range of different definitions of learning expressed by students in the study by Brown et al. (1997). Discomfort with feelings of uncertainty, leading to desire to make sense of their experience may lead students to attempt to negotiate a simplification of their learning experience, or in other words, attempt to identify strategies for 'how to pass' rather than 'how to learn'.

If educators are to promote support for a productive learning cycle, then students need to be motivated and empowered to think and express themselves, and to collaborate/share their ideas. For a similar discussion on learners as problem solvers see Cohen and Nycz (2006). However, we need to recognize that fear of failure may lead individuals to use their creative powers in ways that undermine achievement of such aspirations. Argyris (1990) draws attention to defensive strategies which are sometimes adopted in organizations where conditions of great uncertainty are experienced. Similar strategies may be adopted by students who actively avoided recognizing errors and difficulties, so as to avoid embarrassment which might arise from the challenge of sense-making. For example, students may attempt to obtain very precise instructions on task completion from tutors, rather than engaging in experimentation for themselves. They may seek for 'model answers' or 'recipes' for task completion which are seen to have delivered good marks for other students in the past. One impact of these tactics may be to inhibit opportunities for learning through trial and error, and reflection. Drawing on work by Gregory Bateson (1972), we may perceive a double bind situation to pertain here. As conscious human beings, we have no choice but to reflect on our experience. The question for us all to address, however, is the form this reflection may take. As educators, we would wish students to reflect on what they have learned and how they have learned it, in order to improve their ability as learners. However, by adopting defensive strategies, students concentrate on the content of their learning and neglect process. Consequently, they fail to create a productive spiral which could improve their proficiency as learners, and perpetuate uncertainty into their future student experiences.

At this point, it is useful to consider the possibility of multiple orders of learning (see, for example, Bateson's discussion (1972, p.287)). Argyris and Schon (1978; 1996) describe two distinct orders of learning in terms of single- or double-loop learning. When an individual needs to solve an immediate problem, i.e. close a perceived gap between expected and actual experience, she may harness her sense-making processes within a context of existing goals, values, plans and rules, without questioning their appropriateness. Cope (2006) discusses a similar phenomenon as surface learning as opposed to deep learning. Figure 1 illustrates an assessment process resulting in only single-loop learning.

However, if she goes beyond this to challenge received wisdom and to critically appraise the assumptions previously applied, this may be considered as double-loop learning. We may describe this as creation of a productive learning spiral. Argyris and Schon (1978) themselves describe this process, in the context of organizational learning, as follows:

'When the error detected and corrected permits the organization to carry on its present policies or achieve its presents objectives, then that error-and-correction process is single-loop learning. Single-loop learning is like a thermostat that learns when it is too hot or too cold and turns the heat on or off. The thermostat can perform this task because it can receive information (the temperature of the room) and take corrective action. Double-loop learning occurs when error is detected and corrected in ways that involve the modification of an organization's underlying norms, policies and objectives' ( $\mathrm{p} 2-3$ ). 
Much research has been published which attests to desire felt by educators to improve the quality of student reflection, and engagement with learning through processes of assessment (see for examples, Boud \& Walker, 1998; Morrison, 1996).

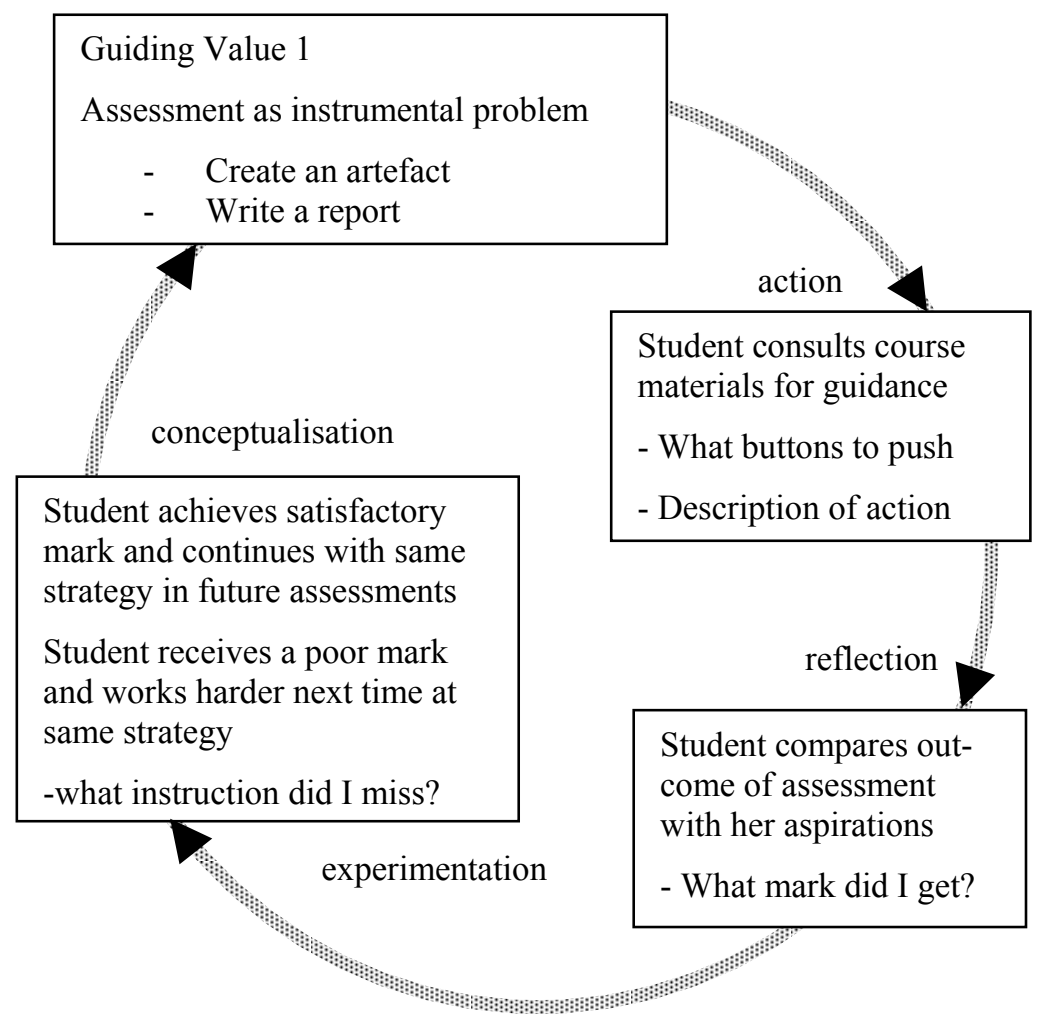

Figure 1. Student assessment as Single-loop learning

Like many of their peers elsewhere, staff of the Department of Creative Technologies found that they were becoming disillusioned with cur-rent assessment practice, which was experienced to be a "create an artifact and write a report" approach. This seemed to be letting students down, in failing to challenge them to think about what they where doing, or why they were doing it. An important factor expressed by staff was that current assessment practice failed to encourage students to construct their own views of the ways in which their work fitted into the subject area as a whole. It appeared that they were not encouraged to do any analysis and evaluation of their work. Each piece drearily recorded what they had done, and what buttons they had pushed. They confused this with analysis and evaluation. Students' work rarely showed evidence of any critical thinking, nor did it relate to the multi- disciplinary area comprising Creative Technologies as a whole. This subject area is very fast moving, and tutors expressed a desire to provide opportunities for students to learn skills that might be adapted beyond the life of current software.

Members of staff expressed a common view that students were not provided with sufficient support to enable them to adopt a reflective approach to their learning. Students who habitually apply a surface-learning approach will not be able to gain access to the higher bands of the University's published assessment criteria, to which they probably aspire. Therefore, methods are needed to stimulate students to reflect and engage in higher orders of learning in order to help them to experience 'success' in their assessments.

It appeared that they lacked a framework that might provide such support during the learning process in general and the assessment phase in particular. Tutors expressed a wish to emphasize 
the relevance of the discussion topics covered in lectures and in practical work, and show how these related to the subject area as whole and, indeed, to other subjects. A belief was expressed that a more holistic approach to assessment might allow the individual topics covered to be related more clearly to each other and more directly to assessed work, and also support University policy on student achievement.

\section{Structuring Uncertainty - Contextual Inquiry}

If learning is experienced by students as a situation of uncertainty, this inevitably involves risk. Defensive strategies described above may be seen as a response to fear generated by unstructured problem-spaces and the risks they entail for participants. In order to promote effective learning, therefore, educators need to support students to create for themselves a reflective learning spiral. Tools and techniques are needed which students may use to help them structure their uncertainty into ambiguity, i.e. to create and develop a range of strategies to enable and support learning, rather than to employ defensive strategies to avoid failure (Bednar, Welch, \& Graziano, 2007).

One method for contextual inquiry which was already familiar to staff in the Department of Creative Technologies was the Strategic Systemic Thinking (SST) Framework (Bednar, 2000). The original purpose for which the SST framework was developed was to assist in organizational sense-making processes and provide support for inquiry leading to a richer knowledge base on which informed action for change might be founded. It is an essential characteristic of investigations using SST that ownership of the ongoing inquiry should rest with the actors themselves. A team of people who facilitate the inquiry will be comprised of actors, and one or more external guides, experienced in systemic methods, who provide support and guidance. The framework supports investigation of a problem space through inquiry into multiple levels of contextual dependencies. Each individual involved is enabled to explore her own unique perspectives. Groups are then supported to examine, and discuss collectively, narratives members have created individually, in order to discover the range of opinion. The aim is not to seek for a consensus, but to create a rich knowledge-base from which informed action could proceed. A range of methods are available to the actors seeking to articulate their worldviews, e.g. creation of rich pictures or role playing in order to support visualization and communication of mental models. The aim is to bring about a constructive dialogue between the actors and the interventee (whoever will be affected by any change resulting from action based on the inquiry).

During 2004 and 2005, the SST framework was used as a basis for inquiry within the Department of Creative Technologies at the University of Portsmouth, in the context of developing a system to support distance learning in the Department. The intervention was initiated by two members of the Department, and they were assisted by an external expert adviser. The actors involved were the other staff members within the Department and the interventee was considered to be the course team(s) who might offer courses by distance learning in the future. Other stakeholders involved included head of department as budget holder; teaching staff; technical support staff; existing and potential students as customers of the proposed development; and representatives of University central management as policy makers.

SST involves three aspects, which are not sequential and may be applied in any order. It is intended to be iterative and it is possible to move from one analysis to another repeatedly and in any direction, at any time. A first pass through the framework may be undertaken in order to promote creation of a version specifically adapted to the requirements of a particular project. The process thus created is then applied in the inquiry. Actors needed to feel empowered and safe within their fields of expertise and responsibility, in order to express their world views. It must be recognized that any intervention involves risk. An individual's sense-making strategies are also dependent upon the organizational culture within which they are set (Schein, 1992). Organizational culture may have a strong influence on what kind of individual autonomy is acceptable. 
One aspect may be termed intra-analysis, focusing on individual perspectives on structuring uncertainty in a perceived problem situation. Individuals are supported to explore their own unique perspectives on contextually-relevant aspects of the problem space in which they are involved. Questions derived during preliminary analysis by members of the inquiry team may be used to empower individuals to explore their situation, using methods such as rich pictures. Figure 2 below shows indicative areas of inquiry used during intra-analysis in the 2004 project in Creative Technologies, together with the dynamics associated with them.

A further aspect of SST is inter-analysis. This part of the inquiry represents a collective reflection on alternative narratives created during intra-analysis, and the aim is to derive and consider the range of world views derived through intra-analysis. No individual perspective is discarded but similar views are consolidated into categories in order to support creation of a dialogue. The purpose is not to achieve a consensus or to establish the common ground.

\section{SST frame work questions for investigation into requirements analysis for educational support for the dept of creative technologies}

\section{The context of the interview questions:}

1. What is education........ from your point of view, in your practice at the moment for your role as a professional in your current situation? (This describes the current situation)

2. What is your aim....... from your point of view in your practice at the moment for your role as a professional in your current situation? (This describes the future situation)

3. What do you see as missing ..........from your point of view in your practice at the moment for your role as a professional in your current situation? (This highlights the critical reflection between 1 and 2)

4. How would you achieve this, or what plan could you see to achieve this? (How can you change your practice, or transform it to achieve this)

The second part of each question is contextually dependent on the first part. The second part provides a vehicle for the individual analyst to critically evaluate her answers to the first part.

Figure 2. An excerpt from the Intra-analysis aspect of inquiry in the Dept. of Creative Technologies, 2004

Perspectives explored and expressed by individuals in intra-analysis create a number of unique narratives about the problem situation. These narratives are then relayed to the group as a whole, either through a collective meeting or some other process. The group then conducts a further contextual inquiry in order to explore the range of opinion. This represents an investigation into contextual dependencies by the whole group, producing a collective map of the problem space from each unique individual point of view. The third aspect of the framework is a value analysis, or evaluation. If analysis represents inquiry into what is unknown, then evaluation represents an examination of what is assumed to be known, i.e. the results of analysis. Here, analysts reflect upon the range of perspectives derived through inter-analysis by considering what they may have overlooked, what they may have under-estimated or over-estimated, and to what extent their individual competences, prejudices, etc. may have impacted on the results of the inquiry. For a fuller discussion of the inquiry conducted in Creative Technologies, please see Bednar, Green, Bain, and Eglin (2004) and Eglin, Bednar, Welch, and Bain (2005). 


\section{Strategic Systemic Learning}

Having had experience of contextual inquiry over a period of two years, staff members in Creative Technologies reflected on its usefulness in structuring perceived uncertainty in problem situations and considered its application for student learning. The approach described here, Strategic Systemic Learning (SSL) has been developed over the last three years, and has been piloted in a level 2 unit taught in the Department (Eglin, 2006). Originally, the teaching team considered using a version of the Strategic Systemic Thinking (SST) framework in its entirety.

\section{Strategic Systemic Learning}

Analysis: (individual) questions for contextually transformation:

Students asked to research $3 \mathrm{D}$ and the web, looking at what are the unique benefits of $3 \mathrm{D}$ and how is this relevant to websites?

You should investigate this under the headings of these particular questions:

A. Where is it used? Where is $3 \mathrm{D}$ on the web currently used and what would you define as $3 D$ ?

B. Where should it be used ideally? Many websites have bells and whistle that are not needed and distract the user. But 3D does have a place, here you are looking at where and what that place is.

C. What is currently missing in its use on the web? i.e. why is it not used where it should be (see2). What resources are available to put 3D onto the web, are they easy to use and freely accessible..?

D. How can it be used more fully used? What need to happen for 3D to be used as in (2)? Is it a software problem, a designer problem a resource problem...?

Discussion: (group):

Class discussion of (analysis above) "in which way are these questions relevant?"

1. What are the other views?

2. How does the group understand the situation?

3. Where are we aiming?

4. How can we get there?

Evaluation: Through reflection by students, individually (in this particular assignment it was not done collectively)

Figure 3. The Strategic Systemic Learning Framework

However, as a special case of an uncertain problem situation, student learning experience was considered to call for a more streamlined approach, to allow the students to engage with it in a relatively short time-scale. The authors hope that the description of SSL given in this paper will lead to developments of further opportunities to assess the framework's adaptation and use. An outline of the SSL framework (as adapted from Bednar, 2000) and the aspects of this new framework are shown in Figure 3.

The adapted framework (SSL) is applied in a teaching and learning environment relating to the Creative Technologies. It is used to help student comprehension and provide them with support for a sense-making process for ordering of the complexity of their subject area. The SSL framework enables integration of specific ideas taught in Creative Technologies, so that individual students may create a perspective of the discipline as a whole within which to place them. It is hoped 
that this analysis will encourage student recognition of the interrelatedness of specific topics, and also enable students to recognize the many reoccurring patterns. One important aim of introducing this assessment method is to embed reflection in student learning processes so that this evolves into a transferable and ongoing learning skill (and support double loop learning, see figure 4).

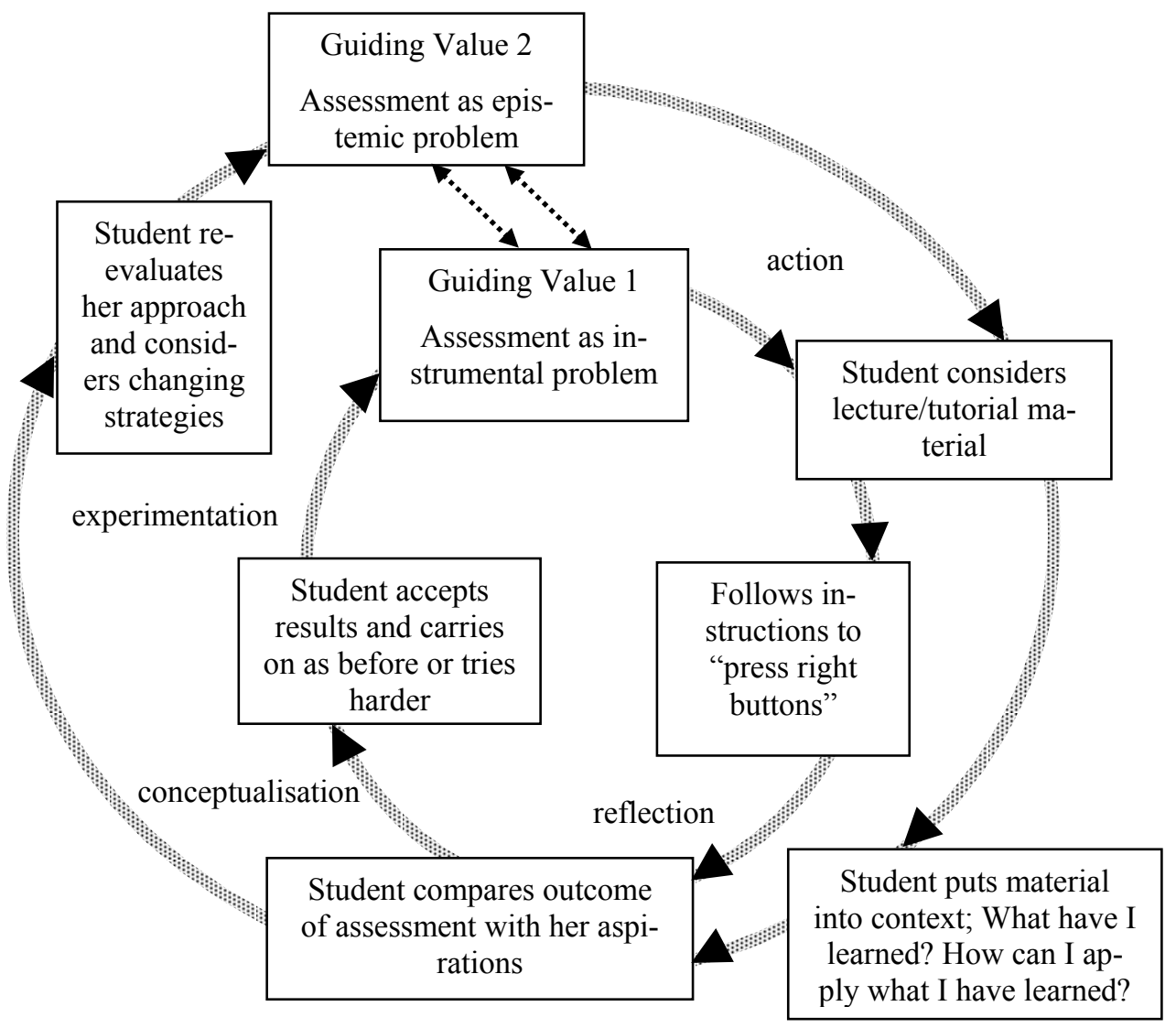

Figure 4. Assessment as double-loop learning.

It has long been recognized that individuals have their own, unique preferred learning approaches and strategies (for a discussion of learning styles, see Kolb, 1984). It has also been pointed out that development of independent skills for deeper learning may be encouraged where students have opportunities for experimentation (see e.g. de Salas \& Ellis, 2006). This is recognized and supported in SSL, since the approach supports individual students to create and develop their own independent learning processes. It also allows students to develop their own topics for study, and even design their own assessment questions either individually or as a group. Unlike some traditional methods, does not penalize students for exploring their own sense-making, by developing and building their own understandings and explaining them. In this way, students are supported to transform their perceived uncertainties surrounding their learning experiences into ambiguity, i.e. create their own alternative knowledge-bases, about Creative Technologies and about learning itself.

The proposed adapted framework supports the use of rich picture and brainstorming as techniques for exploring learning spaces. The SST framework provides a means to structure an uncertainty in a complex organizational learning environment. The area of the Creative Technologies is a complex and constantly changing environment and the SSL provides a means to structure the complex 
learning space which comprises this area. The first step in the process of adaptation is contextualizing of the framework questions.

In initial experiments, this was found to be very challenging for students who experienced the process as very abstract. Accordingly, students where supported in this exercise through dialogue with staff members. The process was therefore adapted to one of gaining agreement on the transformation of the questions by discussing in what ways they might be relevant to student learning.

The framework was discussed at least once a week, on an ongoing basis, through further discussion of the subject area and assessment tasks. The framework was used to organize the inquiry into the subject matter of the unit, and was linked to an assessment artifact that students were required to reference to the analysis and evaluation. The assessment task also asked students to reflect on the learning process, and on the use of contextualized questions.

The authors believe that use of the SSL framework has been successful in providing support to students to take ownership of their own learning. In particular, it has enabled assessment to become an active part of students' learning processes. They have been enabled to move from singleloop learning, associated with instrumental goals of 'passing the unit', to create a more productive learning spiral in which they gain transferable learning skills. This is borne out by comments from the external examiner who says:

'Student work is of a rising standard which is good to see... Clearly, a number of improvements have been made to the unit these appear to be working well and the students are clearly responding positively' (University of Portsmouth, 2006).

Student assessment may provide opportunity for double-loop learning, as shown in figure 4 above. Using the SSL framework, students may be supported to move beyond perception of an instrumental problem (passing the unit) towards consideration of learning processes as an epistemic problem (how to become an independent learner). Through reflection upon her performance in relation to her own aspirations, a student may create a positive learning spiral.

\section{Conclusions}

Through the adoption of the Strategic Systemic Learning framework as an approach to structuring the inherent uncertainties in a learning space, staff members have made it more difficult for students to complete their assessment by adopting oversimplified strategies. Use of this approach requires students to address sets of interrelated questions, encouraging them to consider integration within the whole area of Creative Technologies.

The application of the SSL framework seems to offer many benefits in the context of unit and course participation. First, it gives an opportunity for enhanced student ownership in the assessment process, from the initial problem solving process stages onwards. Secondly, this approach supports students to integrate assessment into the overall learning process, to build their learning competences and thus acquire transferable skills needed in a dynamic technological environment. Since the students structure their work in unique and idiosyncratic ways, plagiarism is less likely to be a problem and would be easy to detect. SSL positively encourages group interactions and discussion and gives students opportunities for formative feedback prior to assessment submission. In this way it supports reduction of their feelings of uncertainty and risk in relation to their studies.

Staff in the Department of Creative Technologies have been encouraged by their pilot use of SSL, and intend to develop this approach further and to introduce its use into other units in the future. 


\section{References}

Argyris, C. (1990). Overcoming organizational defenses: Facilitating organizational learning. Englewood Cliffs, NJ: Prentice Hall.

Argyris C., \& Schön D. A. (1978). Organisational learning. Reading, MA: Addison Wesley.

Argyris C. \& Schön D. A. (1996). Organisational learning II - Theory, method and practice. Reading, MA: Addison Wesley.

Bateson, G. (1972), Steps to an ecology of mind (Pt III). University of Chicago Press.

Bednar, P.M. (2000). A contextual integration of individual and organizational learning perspectives as part of IS analysis. Informing Science Journal, 3(3), 145-156. Retrieved from http://inform.nu/Articles/Vol3/v3n3p145-156.pdf

Bednar, P.M., Green, G.M., Bain, A \& Eglin, R. (2004). Contextual analysis in practice. Proceedings of UK Systems Society International Conference, St Anne's College, Oxford, 7-8 September 2004.

Bednar, P.M., Welch, C. \& Graziano, A. (2007). Learning objects and their implications on learning: A case of developing the foundation for a new knowledge infrastructure. In K. Harman \& A. Koohang (Eds.), Learning objects: Applications, implications \& future directions (Chapter 6). Santa Rosa, CA: Informing Science Press. Available online at http://books.google.com/books?vid=ISBN8392233786\&id=f74CGqX3kP0C\&pg=PP7\&lpg=PP7\&dq= \%22informing + science + Press $\% 22 \&$ sig=PH9VOESGvwn9BRMgJT jepBYXAY

Boud, D. \& Walker, D. (1998). Promoting reflection in professional courses: The challenge of context. Studies in Higher Education, 23(2), 191-206.

Brown, G., Bull, J. \& Pendlebury, M. (1997). Assessing student learning in higher education. Routledge.

Cohen, E. B. \& Nycz, M. (2006). Learning objects and e-learning: An informing science perspective. Interdisciplinary Journal of Knowledge and Learning Objects, 2, 23-34. Retrieved from http://ijklo.org/Volume2/v2p023-034Cohen32.pdf

Cope C. (2006). Beneath the Surface: The experience of learning about information systems. Santa Rosa, CA: Informing Science Press. Available online at http://books.google.com/books?vid=ISBN8392233735\&id=IRN-cTP-WTgC\&pg=RA5PA300\&lpg=RA5-

PA300\&ots=kjsOhUUjkM\&dq=\%22informing + science + Press\%22\&sig=A5JwNQ2cphCE56qqVSLL $\underline{\mathrm{R}-\mathrm{W} 3 \mathrm{nj} \mathrm{U}}$

de Salas, K. \& Ellis, L. (2006). The development and implementation of learning objects in a higher education setting. Interdisciplinary Journal of Knowledge and Learning Objects, 2, 1-22. Retrieved from http://ijklo.org/Volume2/v2p001-022deSalas.pdf

Eglin, R. (2006). Learning in a complex environment: A systems approach to teaching and learning. Proceedings of University of Portsmouth Learning \& Teaching Conference, 19 December 2006. (Poster Session).

Eglin, R., Bednar, P.M., Welch, C., \& Bain, A. (2005). Not avoiding the question of complexity. Proceedings of UK Systems Society International Conference, St Anne's College, Oxford, 8-9 September 2005.

Gackowski, Z. J. (2003). Case / real-life problem-based learning with information system projects. Journal of Information Technology Education, 2, 357-365. Retrieved from http://jite.org/documents/Vol2/v2p357-365-128.pdf

Kolb, D. A. (1984). Experiential learning: Experience as the source of learning and development. Englewood Cliffs, N.J: Prentice-Hall.

Milne, A. A. (2006). Winnie-the-Pooh. $80^{\text {th }}$ anniversary edition. Egmont Books Limited.

Morrison, K. (1996). Developing reflective practice in higher degree students through a learning journal. Studies in Higher Education, 21(3), 317-332. 
Ramsden, P. (2003). Learning to teach in higher education (2nd ed.). Routledge.

Schein, E. (1992). Organizational culture \& leadership (2nd ed.). Jossey-Bass.

University of Portsmouth (2006). Examiners report dated 29th June 2006. Faculty of Creative Industries, Registry. University of Portsmouth.

Weick, K. (1995). Sense-making in Organizations. Sage.

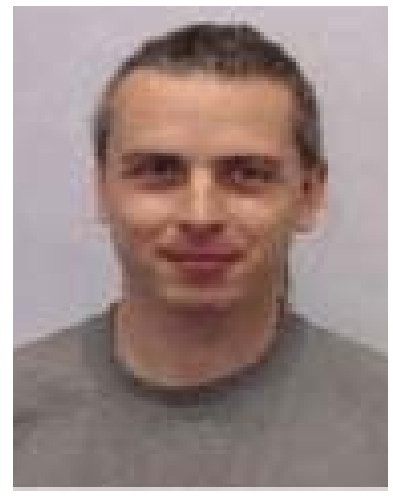

\section{Biographies}

Peter M Bednar is an engineer and senior lecturer with several years of experience from industry in systems analysis and development. Since 1997, he has been working as an academic. His research covers contextual analysis, organizational change and information systems development, and he has published several book chapters and many articles in these fields. He is currently a Senior Lecturer in the School of Computing at the University of Portsmouth, UK and is also affiliated to the Department of Informatics at Lund University, Sweden.

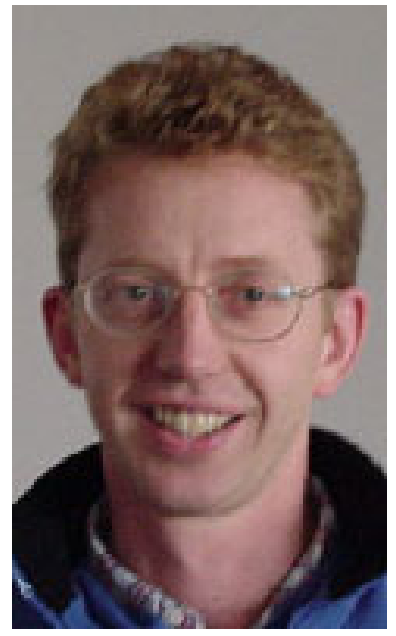

Roger Eglin is a course leader for BSc in Computer Animation. He has been working as an academic since 2001. He is a Senior Lecturer at the Department of Creative Technology at the University of Portsmouth. He has a background in Biochemical Engineering and Information Systems. His research interests cover game applications, health and education.

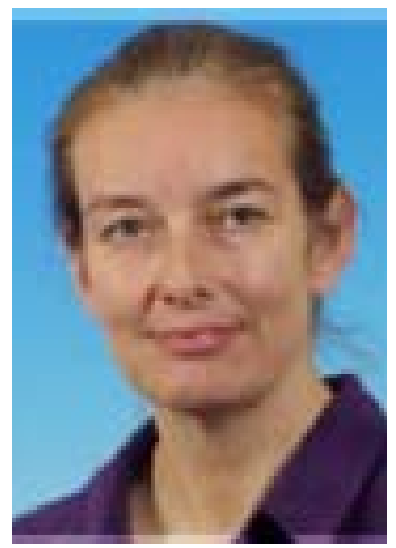

Christine Welch is a Principal Lecturer in the Department of Strategy and Business Systems, part of the Business School at the University of Portsmouth, UK. Her research interests include critical systemic thinking, contextual analysis and organizational change, and she has published several book chapters and articles in these fields. She is convenor of the Southern Regional Centre of the UK Systems Society. 